Neuropeptides 5: 213-216, 1984

\title{
ELECTROENCEPHALOGRAPHIC ASSESSMENT OF THE ROLE OF $\&$ RECEPTORS IN OPIOID PEPTIDE - INDUCED SEIZURES
}

Frank C. Tortella, Lydia Robles, Henry I. Mosberg and John W. Holaday. Neuropharmacology Br., Division of NP, Walter Reed Army Institute of Research, Washington, D.C. 20307-5100 and Department of Medicinal Chemistry, College of Pharmacy, University of Michigan, Ann Arbor, MI 48109 (reprint requests to F.C.T.)

\section{ABSTRACT}

DPDPE ([D-Pen ${ }^{2}$, D-Pen $\left.\left.{ }^{5}\right]-E n k e p h a l i n\right)$ and DPLPE ([D-Pen $\left.\left.{ }^{2}, L-P e n^{5}\right]-E n k e p h a l i n\right)$ are conformational ly-constrained cyclic analogs of enkephalin with high selectivity for $\delta$ opioid receptors. Intracerebroventricular (i.c.v.) administration of each analog acutely produces a complex EEG response in rats characterized by a dose-related increase in spectral power and HVSA (peak frequency of $5.0 \mathrm{~Hz}$ ) during behavioral stupor, and a thet a driving (5 25-8.0 Hz) associated with intense behavioral arousal. These effects were antagonized by high $(10 \mathrm{mg} / \mathrm{kg})$, but not low $(1.0 \mathrm{mg} / \mathrm{kg})$, doses of naloxone. Both analogs falled to cause EEG or convulsive seizures. In contrast, i.c.v. administration of DADLE ([D-Ala $\left.\left.a^{2}, D-L e u^{5}\right]-E n k e p h a l i n\right)$, an enkephalin analog with activity at both $\mu$ and $\delta$ binding sites, caused initial nonconvulsive EEC seizures followed by HVSA $(3.0 \mathrm{~Hz})$; theta driving was not evident. The incidence of the seizures was dose-related and antagonized by very low doses of naloxone $(0.01-1.0 \mathrm{mg} / \mathrm{kg})$. Collect ively, the inability of DPDPE and DPLPE to cause seizure activity, and the marked sensitivity of DADLEinduced EEG seizures to naloxone, suggest that $\delta$ receptors are not directly responsible for DADLE-induced EEG seizure activity. Furthermore, these data implicate $\mu$ opioid receptors as the primary sites responsible for enkephalin-induced seizures.

\section{INTRODUCTION}

Central administration of opioid peptides causes a sequence of electroencephalographic (EEG) responses characterized by an initial nonconvulsive EEC seizure, a subsequent sustained period of high-voltage slow-wave activity (HVSA) and a final short phase of low-amptitude desynchronized EEG activity prior to sleep $(1,2,3)$. The seizurogenic properties of opioid peptides have received considerable attent ion, and it has been suggested that opioid peptide-induced seizure activity is mediated by the $\delta$ receptor subtype of cerebral opioid binding sites $(1,4,5$,$) .$

Whereas the existence of multiple opioid receptors has been firmly established $(6,7)$, it remains difficult to establish with certainty that a particular response is mediated by a single subtype of opioid receptor, the major obstacle being the unavailability of highly selective agonist ligands. Recently, cyclization of the enkephalin molecule and conformational constrainment with a bis-penacillamine bridge in positions two and five has resulted in highly selective ligands for the 8 opioid receptor subtype (8). In the present study, we have used these novel compounds to assess the role of $\delta$ receptors in opioid peptide-induced seizures. In addition, we have studied the EEC effects of DADLE, 
a less selective enkephalin analog which binds equally well to $\mu$ and $\delta$ sites (9).

\section{METHODS}

Male Sprague-Dawley rats (250-300g), maintained on a timer-regulated lights-of $f$ period $(0600 \mathrm{hr}-1800 \mathrm{hr})$, were surgically prepared with chronic bipolar epidural frontoparietal electrodes and a right lateral (i.c.v.) cannulae(2). Animals were allowed 57 days to recover from surgery before testing.

During testing all rats were housed in individual recording chambers. Each chamber was equipped with a specially designed mercury swivel commutator (Walter Reed Div, of Instrumentation), providing noise-free recording contacts and permitting unrestrained movement of the rat during EEG monitoring. EEG activity, filtered to pass frequencies between 1 and $35 \mathrm{~Hz}$, was continuously recorded during each test session on a Grass Model 7 polygraph. The EEC was simultaneously stored on FM tape for subsequent analysis. Power spectral analysis was performed online during each experiment using a Nicolet Pathfinder $\mid 1$ computer system. Briefly, sequential EEC power spectrum arrays were derived from consecutive $12 \mathrm{sec}$ epochs of cortical activity obtained after saline and drug treatment. The EEG was digitized at a rate of $256 / \mathrm{sec}$, and spectral densities were estimated at $0.25 \mathrm{~Hz}$ intervals from zero to $20 \mathrm{~Hz}$.

DADLE, DPDPE and DPLPE were dissolved in sterile saline and injected i.c.v. over $45 \mathrm{sec}$ using a Hamilton microliter syringe. Total injection volumes never exceeded $10 \mu \mathrm{l}$. Ten to $30 \mathrm{~min}$ prior to drug injections, each rat received an i.c.v. saline injection and thereby served as its own control In the naloxone studies, the antagonist $10.01-10$ $\mathrm{mg} / \mathrm{kg}, \mathrm{s.c.}$ ) was given $10 \mathrm{~min}$ prior to the agonist. All rats were given only a single i.c.v. injection series (saline and peptide), and each experiment was monitored until the appearance of slow-wave sleep (SWS).

\section{RESULTS}

Within 1 min following its injection, the cyclic enkephalins (35-140 nmol, i.c.v.) produced an HVSA with a maximal increase in total power of $253 \%$ to $286 \%$ of control. At the highest dose tested (140 $\mathrm{nmol})$, the HVSA lasted approximately 15-30 min and had a mean peak frequency of $4.75 \mathrm{~Hz}$ to $5.0 \mathrm{~Hz}$ with very little EEG activity above $13 \mathrm{~Hz}$. At these doses the rats were awake but stuporous. The HVSA was followed by a prolonged period of EEC theta-driving (peak frequency ranging from $6.75-7.5 \mathrm{~Hz}$ ) which was associated with an intensely aroused behavioral state characterized by locomotor activity and rearing with no grooming or eating. The effects of DPDPE and DPLPE were dose-related and antagonized by high doses of naloxone. These data are summarized in tables 1 and 2 .

In contrast, the i.c.v. administration of DADLE (4.4-35 nmol) caused an initial nonconvulsive EEC seizure temporally associated with wet-dog shake behavior. At the highest dose tested $(35 \mathrm{nmol})$ the seizure activity had a peak frequency of $1.75 \mathrm{~Hz}$ and a marked increase in spectral power in the 13 to $30 \mathrm{~Hz}$ band. The EEG seizures were followed by HVSA with a maximal increase in total power to $451 \%$ of control and a peak frequency of $3.0 \mathrm{~Hz}$. During the HVSA, the animals were immobile with extreme muscle rigidity. A short period of intermittent arousal dominated by eating and grooming followed the HVSA. However, no theta activity was seen (table 1). DADLE's effects lasted approximately $40 \mathrm{~min}$. Unlike the cyclic analogs, the EEC effects of DADLE were very sensitive to naloxone. In particular, the DADLE-induced seizures were attenuated by doses of naloxone as low as $0.01 \mathrm{mg} / \mathrm{kg}$, s.c. These data are summarized in table 2 . 
Table $1_{i}$ Summary of the EEG effects of i.c.v. administered DADLE, DPDPE and DPLPE in rats.

\begin{tabular}{lcccc}
\hline Compound & $\begin{array}{c}\text { Dose Range } \\
\text { (n mol) }\end{array}$ & $\begin{array}{c}\text { EEG Seizures } \\
\text { (\% Responding) }\end{array}$ & $\begin{array}{c}\text { HVSA } \\
(\% \text { Power })\end{array}$ & $\begin{array}{c}\text { Theta Driving } \\
(5.25-8.0 \mathrm{~Hz})\end{array}$ \\
DADLE & $22-35$ & $71(1.75 \mathrm{~Hz})^{3}$ & $451 *(3.00 \mathrm{~Hz})$ & $\ldots$ \\
DPDPE & $35-140$ & 0 & $253^{*}(5.00 \mathrm{~Hz})$ & $+++(6.75 \mathrm{~Hz})$ \\
DPLPE & $35-140$ & 0 & $286^{*}(4.75 \mathrm{~Hz})$ & $+++(7.50 \mathrm{~Hz})$ \\
\hline
\end{tabular}

1 n=14 rats per group.

2 Maximal increase in total power ( $\%$ of control) during high-voltage slow-wave activity (HVSA).

3 Mean peak frequency.

$P<0.01$ with respect to saline control ( Paired $t-t$ est).

Table 2. The effect of naloxone on DADLE- and DPDPE-induced EEG responses in rats. ${ }^{1}$

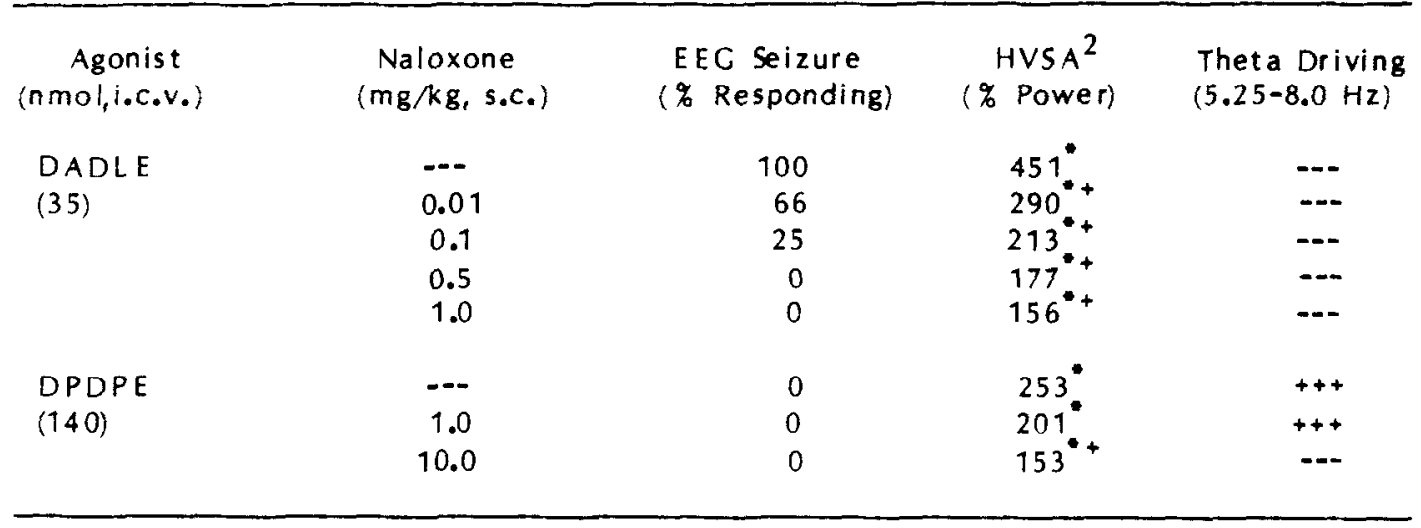

$1 n=3-5$ rats per group.

2 Maximal increase in total power ( $\%$ of control) during high-voltage slow-wave ąctivity (HVSA).

$P<0.01$ with respect to saline control (Paired $t$-test).

${ }^{+} P<0.05$, at least, with respect to agonist alone (Dunnett's test for multiple comparisons).

\section{DISCUSSION}

DPDPE and DPLPE have been described as selective o opioid receptor agonists both in vitro $(8,9)$ and in vivo $(10)$. Using these peptide ligands we have attempted to ascertain the contribution, if any, of $\delta$-receptor activation in opioid peptide-induced seizures. Our results have falled to demonstrate any direct role for activation of $\delta$ opioid binding sites mediating the nonconvulsive EEC seizures reported here. Moreover, the EEG seizure activity produced by DADLE, a $y$-and o-directed ligand, was highly sensitive to naloxone antagonism, suggesting that these seizures are possibly the result of activation of $u$ (naloxone-sensitive) binding sites. 
Previous reports have suggested that the EEC seizures produced by opioid peptides may be a consequence of $\delta$ receptor activation $(1,4,5)$. However, the "prototypical " $\delta$ ligand used has been DADLE which, as noted earlier $(9,10)$, shows selectively for $\mu$ sites as well as $\delta$ sites. Additionally, thorough naloxone dose-response studies have not been carried out such that a true determination of the relative naloxone-sensitivity of DADLE-induced seizures could be established. In the present study, doses of DADLE as low as $4.4 \mathrm{nmol}$ caused epileptiform EEC activity which could be antagonized by very low doses of naloxone (minimal effect ive dose was $0.01 \mathrm{mg} / \mathrm{kg}$ ).

All three ligands tested caused a similar HVSA and stuporous behavior in rats. However, power spectral analysis of the EEG clearly revealed discrete differences in spectral patterns evoked by DADLE and the cyclic analogs with regards to power and frequency distribution. Also, higher doses of naloxone were required to antagonize DPDPE- and DPLPE-induced HVSA than DADLE-induced HVSA. The s selective cyclic enkephalins also differed from DADLE in producing a marked theta driving. This inability of low doses of naloxone to antagonize this DPDPE- and DPLPE-induced activity is suggestive of a non- $\mu$ (possibly $\delta$ ) receptor involvement.

In summary, while i.c.v. administration of DPDPE, DPLPE or DADLE produces a complex EEG response in rats, there is no evidence to suggest that the DADLE-induced nonconvulsive EEC seizures are a result of $\delta$ receptor activity. Furthermore, given the results obtained with DPDPE and DPLPE, and the naloxone sensitivity studies, it appears that $\mu$ receptors represent the primary binding sites responsible for enkephalin-induced seizures.

\section{REFERENCES}

1. Urca, C., Frenk, H., Liebeskind, J.C. and Taylor, A.N. (1977). Morphine and enkephalin: analgesic and epileptogenic properties. Science 197: 83-86.

2. Tortella, F.C., Moreton, J.E. and Khazan, N. (1978). Electroencephalographic and behavioral effects of $\mathrm{D}$-ala ${ }^{2}$-methionine enkephalinamide and morphine in the rat. 1. Pharamcol. Exp. Ther. 206: 636-643.

3. Henriksen, S.J., Bloom, F.E., McCoy, F. et al. (1978). B-endorphin induces nonconvuls ive limbic seizures. Proc. Nat l. Acad. Sci. $75: 5221-5225$.

4. Dzoljic, M.R. and Poel-Heisterkamp, A.L.v.d. (1982). Delta opiate receptors are involved in the endopioid-induced myoclonic contractions. Brain Res. Bull. 8: 1-6.

5. Frenk, H. (1983). Pro-and anticonvulsant actions of morphine and the endogenous opioids: Involvement and interactions of multiple opiate and non-opiate systems. Brain Res. Rev. 6: 197-210.

6. Wuster, M., Schulz, R. and Herz, A. (1981). Mult iple opiate receptors in peripheral tissue preparations. Biochem. Pharmacol. 30: 1883-1887.

7. Martin, W.R. (1984). Pharmacology of opioids. Pharmacol. Rev. 35: 285-323.

8. Mosberg, H.l., Hurst, R., Hruby, V.l. et al. (1983). Bis-penacillamine enkephalins show pronounced delta opioid receptor selectivity. Proc. Natl. Acad. Sci. 80: 58715874.

9. James, I.F. and Coldstein, A. (1983). Site-directed alkylation of multiple opioid receptors. Mol. Pharmacol. $25: 337-342$.

10. Porreca, F., Mosberg, H.l., Hurst, R. et al. (1984). The roles of mu, delta and kappa opioid receptors in spinal and supraspinal medication of gastrointestinal transit effects and analgesia in the mouse. J. Pharmacol. Exp. Ther. 229: In Press. 